\title{
University Interdisciplinary Research Organizations in the Process of Collaborative Innovation: Advantages, Difficulties and Strategies
}

\author{
Ying $\mathrm{Bi}^{1} \&$ Liansheng Yang ${ }^{1}$ \\ ${ }^{1}$ Higher Education Research Center, Faculty of Humanities and Social Sciences, Dalian University of Technology, \\ Dalian, China \\ Correspondence: Liansheng Yang, Faculty of Humanities and Social Sciences, Dalian University of Technology, \\ Liaoning Dalian, 2 Lingong Road, China. Tel: 86-139-9953-3272; 86-411-8470-7554. E-mail: biyingdut@126.com
}

Received: November 23, 2014

Accepted: December 10, 2014

Online Published: December 15, 2014

doi:10.5430/ijhe.v4n1p71

URL: http://dx.doi.org/10.5430/ijhe.v4n1p71

\begin{abstract}
Under the background of collaborative innovation, interdisciplinary research organizations due to its structural advantages should actively target frontier science and the great needs of national development, key research and strategic issues of solving the country's need, prospective issues in the frontier of science and technology and major welfare issues related to people's livelihood. And it requires reasonable localization of interdisciplinary research organizations in universities. Facing the difficulties participated in collaborative innovation, they should establish a perfect operation mechanism, play the role of collaborative innovation platform, and actively transform to collaborative innovation center scientifically and effectively.
\end{abstract}

Keywords: Collaborative innovation, University interdisciplinary research organizations, Collaborative innovation platform

\section{The advantage of collaborative innovation in university interdisciplinary research organizations}

The collaborative innovation of interdisciplinary research organizations is an organizational behavior that proceeds knowledge innovation with university interdisciplinary research organizations and enterprises, among many anticipate. The key is effective coordination, the premise of effective collaboration is to build a reasonable organizational structure and operation mechanism. Therefore, this collaborative innovation itself has many advantages:

1.1 The inherent advantages of the platform. Today, Many major technological innovations, such as nanoscience, genetic engineering, lunar probe project and so on, all are typical engineering of interdisciplinary research. In the process of collaborative innovation, the first priority is establish collaborative innovation platform , Interdisciplinary research is an important way to collaborative innovation, innovation goals only identify the participating subjects can have the basic of cooperation. collaborative innovation only carry out interdisciplinary research can have the real meaning .According to "Higher Education Institutions Innovation Ability Promotion Plan" (hereafter referred to as "2011 Plan"), collaborative innovation platform must be able to promote interdisciplinary research, contribute to different disciplines effective integration. University should encourage each college stand on a higher altitude, put more attention into the edge and cross-disciplinary area, and integrate multi-disciplinary research methods, find more innovative basis points (Ye Shi man,2012).

Therefore, the university should use the "2011 Plan" as an opportunity to firmly grasp the initiative, collaborative innovation as a breakthrough; through the reform mechanism, break the closed status quo of independent innovation, integrate internal school resources effectively, optimize resource allocation, encourage teachers exchange and cooperation cross colleges, interdisciplinary, cross-platform. University interdisciplinary research organizations which has the inherent advantages of collaborative innovation, interdisciplinary research organizations is a good ready-made collaborative innovation platform, on this platform, it encourage researchers to carry out interdisciplinary research, and ultimately achieve collaborative innovation.

1.2 The advantage of effective integration in resources. Innovative resource elements integrated and interdisciplinary research is the prominent feature of collaborative innovation. university interdisciplinary research organizations participate the process of collaborative innovation and interdisciplinary research organizations already have given different collaborative innovation subject provides an interdisciplinary research of collaborative innovation platform, 
In this collaborative innovation platform, from the state, society, industry, etc. a variety of innovative resource elements, such as funds, equipment, manpower and other factors, which concentrated together to achieve economies of scale organic integration through research and development activities, increasing the possibilities of collaborative innovation success, while reducing the risk of failure. Participate in collaborative innovation between each main body through constant communication and exchange, to achieve the sharing recessive resources of technology, knowledge and information, etc. so as to perform scientific and technological innovation between different main subject, collaborative innovation process promotes the formation of knowledge diffusion channels, which help to transfer knowledge and technology

1.3 Transaction cost savings and information symmetry advantage. In the process of collaborative innovation, to achieve effective gathering between different main synergy subject of innovation elements, all the resource elements should run on the same collaborative innovation platform to avoid repeat purchasing the same equipment problems during the process of collaborative innovation, improve R\&D equipment utilization, can effectively reduce the unit cost of R\&D projects, optimize the allocation of resources. In addition, due to the different main collaborative innovation cooperate with university interdisciplinary research organizations running on this platform together, forming a specialized division of labor, accelerate the speed of obtaining innovation resources, which can avoid the cost of searching for information on innovative technologies. Meanwhile, reduce transaction costs, the information of each main collaborative innovation subject can achieve effective symmetry, laying a good foundation of knowledge production channels for information, dissemination and metastasis.

\section{The dilemma of Chinese University Interdisciplinary Research Organizations collaborative innovation}

In the national innovation system, the university as a body of knowledge production has an important position and play a unique role, especially interdisciplinary research organizations internal university, active collaboration with the business community and government, for carrying out a higher level, a deeper collaboration innovation has laid a good foundation. But from cooperation to synergy achieve the common goal of cooperation parties in the process, due to the affect of some factors, such as the knowledge characteristics in the cooperation, knowledge structure of each cooperation parties, the willingness of knowledge sharing, the selection of transfer channel to the knowledge and so on, the contradictions between each cooperation parties starting occurrence, it is difficult to play each advantage to come to an effective collaborative innovation mechanism ,achieve the common goal of collaborative innovation

2.1 The knowledge characteristic of each subject present heterogeneity, and they lack of positivity and initiative. During the process of collaborative innovation in the university interdisciplinary research organization, the core subject of their cooperation are mainly research institutes and enterprises in order to realize the function complementary and resource complementary. However, the university interdisciplinary research organizations scientists mainly base on academic research, enterprise and nation aren't understand deep enough to the needs of new knowledge, it is very difficult for enterprise and nation needs to achieve butt joint. This is because the university interdisciplinary research organizations, research institutes product the new knowledge has application.

The academic of this evaluation determine the content of academic incentive mechanism, universities often too "academic" for academic evaluation, emphasize theory, light application, emphasize academic profound and preciseness (discipline-based), light interdisciplinary practical application, this evaluation guide hurt the enthusiasm , passion and creativity of many scientific researchers who carry out the interdisciplinary collaborative innovation, caused the collaborative innovation insist on business-oriented, market-oriented, face the practical application bear the great risks and pressures(Li Zuchao \& Liang Chunxiao,2012). Thus, university interdisciplinary research organizations, the researchers of research institutes should pay more consideration is a high-level subject, the number of patent and academic paper, not the transformation, application and extension of scientific research.

In reality, if the university interdisciplinary research organizations and enterprises, didn't form a good knowledge requires communication mechanism, lack of positive and initiative of cooperation, and the end result is the "two skins " that cooperative forms of universities, research institutes and enterprise, do their own work, let alone collaborative innovation.

2.2 Benefit sharing mechanism is difficult to establish, knowledge sharing willing is not strong. Interdisciplinary cooperation with other research organizations should achieve from cooperation to synergies, each cooperation subject should achieve the real knowledge sharing, product new knowledge together to meet the mutual needs of cooperation subject, this need the benefits of cooperation subject come to an agreement. As far as university interdisciplinary research organizations whose main interest is not money, but in the collaborative process, whether to produce new knowledge and new technology enterprises need, whether to meet the needs of the society, improve 
the scientific ability and level of researchers, played a social service functions of universities' mainly academic interest.

Enterprise which is the applicant of new knowledge and new technology often pursue maximum economic benefits, and its function is to turn new knowledge and new technologies into commercial products to achieve industrial production, following the laws of the market. In addition, our existing decentralized administrative system, universities, research institutes, and enterprise administrative units are different, different units have different system, institutional barriers too difficult to carry out unified planning, management and coordination and difficult to integration of resources effective. Therefore, the main communication mechanism of each cooperation subject like universities, research institutes and enterprises, etc. it is very difficult to establish resource sharing mechanism, evaluation mechanisms, and incentives mechanisms, unable to reach a knowledge-sharing, let alone conduct the new knowledge which product, spread and transfer

2.3 The choice of knowledge production and knowledge transfer channels are too arbitrary, it is difficult to build a substantive platform for participants. Right now, the main form of university knowledge transfer channels are mainly the form of technology transfer collaboration, cooperative development and commission development, etc. According to the related investigation that collaborative innovation of China's enterprises universities and research institutions, about $37 \%$ are regular technical advice, $33 \%$ was commissioned development contract(Yan Xiong,2007). as far as university of interdisciplinary research organizations and research institutes, the property belongs to the academic organizations, its personnel assessment, job promotion, salary incentives and so on mainly accordance with the evaluation mechanism of academic organizations, so for them, their knowledge production and knowledge transfer channel selectivity is very big, only follow the evaluation mechanisms of inner unit

While companies need knowledge and skills with a strong practicality, once knowledge (technology) transfer successfully, we can achieve commercialization scientific research achievements. The reality is that, for the cooperative subject, the choice of knowledge production and knowledge transfer channels are too arbitrary, it is difficult to build a cooperative platform between the participation subject. And come into collaborative innovation, requires an interdisciplinary university research organizations, research institutes or companies for a project with a joint research and development, and build confident system in the process, in order to achieve long-term cooperation mechanism.

2.4 Knowledge innovation environment is Imperfect and cooperative security system is unsound, should establish a long-term mechanism for collaborative innovation between universities, research institutes and enterprises, need a good environment of knowledge innovation, can't leave these sectors like government departments, agencies and banks. Although the government introduced a number of policies, these content policies lack of the specific regulations and implementing rules of industry research collaborative innovation, the real operational missing. Another is lack of intermediary, to achieve true cooperation towards collaborative innovation between universities, research institutes and enterprises, can't leave the agency. This agency can be a government agency, also risk investment institutions, it is not a general sense as "matchmaker" for agency, but predicted that such cooperation will bring some kind of income for the state or itself. Third is the banking sector. Enterprises in process of great technology project development needs the funds of the banking sector to support.

\section{The scientific optimization strategy of collaboration innovation in university interdisciplinary research organizations}

University interdisciplinary research organizations as a collaborative platform for innovation in collaborative innovation process need a suitable collaborative innovation mechanism to get the main resources, information and personnel of each collaborative unit involved into the platform of collaborative innovation to accomplish collaborative innovation goals. However, such as universities, research institutes and enterprises, these cooperative bodies belong to different stakeholders with their own pursuit of value, and they cannot form a collaborative innovation. Then the collaborative innovation depends on the good long-term operating mechanism.

3.1 Strategy One: research projects should meet the demands. "Collaborative innovation either take a modular approach (such as contract research outsourcing, project consulting) or a embedded approach (such as new-joint venture company, participation in national projects, personnel exchanges and training), which both require cooperation between the parties to find their own roles in the innovation chain, to make clear their concerns and resource advantages, to arrange the division of labor between partnership strategically to achieve organic connection of disciplines chain and industrial chain(He Yubing,2012). "To reach common objectives and effective collaborative innovation between Academia and industry, the common goal should be the primary. If there is no agreement in common goal, then collaborative innovation cannot be achieved. Common goal collaborative innovation is embodied 
in the research project.

There are two questions. Firstly, whether this research project operated by university truly meet the needs of the University. Secondly, whether or not the companies' needs can be really met when they are participated in this project. It is not only the common demand achieved both by universities and companies that universities and companies can cooperate hand-in-hand. Also it is possible to realize the collaborative innovation and complete the research project together. Therefore, universities should play their strengths in terms of discipline, talent, etc., and transform these needs into the driving force of knowledge innovation. Also universities should establish a lasting and stable linkage with industry and new department, accurately have an idea of the scientific innovation needs of industries and other sectors of the community, and change the idea that the research topics proposed is solely relied on the researcher's own understanding. While the research projects should be based on the following reality issues, such as national strategy, social issues, industrial development and cultural heritage of innovation. Research topic, determining the problem tendency, should be both to "heaven" and "site", which means academic and reality, and move each participating body around a common goal to carry out collaborative research and innovation.

The market supply and demand of collaborative innovation consist of the need to diffusion of university knowledge and the source for enterprises to innovate technology(Lu Ruoyu,2002). However, the formation of market supply and demand is far from enough, and it is more necessary to balance the supply and demand of the participants. So, in order to really make the industry proactively participate in collaborative innovation over the course of collaborative innovation in university interdisciplinary research organizations, the primary key is the exact butt between college knowledge innovation and enterprise technology innovation. New knowledge transformed from university can be applied in enterprise technology innovation, and cooperation expectation associated with respective needs come to an agreement. Therefore, the university knowledge innovation needs and the enterprise technology innovation needs are embodied in the formation of research purpose.

Since universities and other research institutions are lack of accurate positioning for the real market need in the scientific research process, pertinence and modeling, most researches are only able to produce a "test" or "technical" achievement. That consequence is different from the "production" or "market-based" outcomes which the enterprises need, and it leads to the disjunction between technology supply and demand(Luo Yan,2009). In fact, in the national innovation system, universities, research institutions and enterprises belong to different areas, possess different functions, and take on clear division of innovation functions. They are also different from each other in terms of resources, talents, technology, and shortage of innovation elements.

From the macro aspect, universities should meet the national strategic needs, the industrial development demand, and the socio-economic development and cultural heritage need, to promote national strategies and social economic development. From the micro aspect, the purpose of interdisciplinary research organizations research projects is not only to help enterprises solve internal technical innovation, technology research development, but also to provide enterprise with new knowledge for entering new strategic technology areas and exploiting new products with high technology, standing in the height of the global industrial and economic development of the country. In addition, the university's interdisciplinary research projects should also come from aging, environmental pollution, health care, energy and other national economy and social issues. Through the study of these social issues and under the guidance of these issues, it is possible to solute the social problems and promote social development.

As technology innovation become the key to business competition, more and more companies began to pursue industrial generic technology or cutting-edge technology to enable exploratory research and demand-driven research closely related, which offer the opportunity for cooperation among the University closing to frontiers of knowledge, enterprise closing to market and systematic resource advantage(Zhang Yuchen,2011). For the university, if they want to be a dominant position in collaborative innovation, they must give full play to their advantages in terms of disciplines, talents, convert the strategic demand from local place and country into force of innovation and development, and highlight the original innovation, joint innovation, and recreation. When they get a series of outcomes with elementary, original and landmark features, it can support and lead the industry to innovate. Therefore, for the industrial needs and social needs to solve practical problems, it is possible to attract the industry's interest to participate in research projects and to achieve collaborative innovation.

3.2 Strategy two: the distribution of benefits should match the risk sharing. The distribution of benefits of interdisciplinary research organizations during the collaborative innovation is the most important issue, playing a decisive role in the sustainable and stable development of cooperation. There is a consensus about the distribution of benefits only if each unit participated in the collaborative innovation arrives an agreement in terms of benefit, finds its own interest point, and achieves its own interest in the process of collaborative innovation. In the collaborative 
innovation process, participating bodies are equal and their rights and obligations are the same. Consequently, the most reasonable distribution of benefits should refer to the following rules: firstly, before the whole work, there should be a research and development contract. Secondly, before the collaborative cooperation start, the obligation of each participating body and profit returns should be remarked in the research and development contract. For example, the pricing research, property ownership of technological achievements, stakeholders, and internal allocation must be clear. It is necessary to make clear of the benefit distribution reasonably.

Distribution of benefits is directly related to the real benefit which each participating body gets from the collaborative innovation. If this issue is not properly handled, it will hurt the benefit which individual deserves to get, and it may cause the talent losses, making a heavy benefit losses. Obviously, the distribution of benefits directly affects the cooperation. The distribution of benefits is the fundamental driving force to promote the university interdisciplinary research organizations to achieve collaborative innovation, and the key point of benefit distribution is to share benefits and risks.

Universities have advantages in terms of the basic research, professionals, academic knowledge and research methods, and its main demand are to obtain research and development funds and practical information. While enterprises have advantages in terms of plenty of finance support to innovate, production and test equipment and rapid commercialization of technology, market information and marketing experience. What they need is knowledge and human resources. There is no competitive relation between universities and enterprises' interests. So the critical point is to choose the core interests of both sides. University interdisciplinary research organizations at the process of collaborative innovation should build and perfect a scientific reasonable benefit-sharing mechanism to provide all involved units with a mutual-benefit distribution mechanism in a symmetrical institutional framework. Meanwhile, profit-driven is the most fundamental source of power for each subject involved to work on the collaborative innovation of university interdisciplinary research.

In the process of collaborative innovation of university Interdisciplinary research organizations, although the interests of the individuals involved in the research are different from each other, but it can be compatible with each other. For universities, its main purpose is to get scientific financial assistance from enterprises by transforming their new knowledge to productive department, including technology and patent outcomes, access to business-university scientific research products, and to improve their scientific environment. Through that, the scientific research can move toward the sophisticated technology research, foster the talent cultivation at the same time, and promote the executive ability and scientific research ability at a great level.

Considering the corporate, through collaborative innovation, they can get complementary outcomes mixed with resources and research outcomes, acquire scale merit to get bigger profit, cut down the R\&D risk, solve the problems about technology innovation and project development, and curtail the time which product from R\&D market. If research technologies and technology patents of universities belong to Strategic emerging industry of science and technology, once the enterprises have access to those new technology and patents, they can enter the new technology are, exploder new products, and monopolize the technology. Companies can bring up their R\&D staff who are participated in the collaborative innovation process to practical talents to meet the reality needs at the same time. So companies not only get profit in a short time also accumulate human resources in technology and science for future development.

Therefore, in the term of the distribution of benefits, the next rules should be followed. Firstly, participated members should share outcomes and resources, bear risks, and promote common development. Secondly, it is necessary to arouse the activity of each unit, to switch the innovative programs from individual, closed way to the flow open way. Thirdly, it is necessary to promote the innovation elements to convergence, integration from an isolated, dispersed state, and to get a win-win state.

3.3 Strategy three: Performance evaluation should meet the cooperative target. Objective performance evaluation is an necessary condition for achieving interdisciplinary research organizations' collaborative innovation goals, and performance evaluation is a key of university interdisciplinary research organizations' collaborative innovation. Performance evaluation after the finish of research program is to link the collaborative performance and profit distribution, to evaluate the execution of the research project including each participated member, and to ensure the right of each unit to be protected. Therefore, the main function performance evaluation's is to ensure the distribution of benefits of each cooperative body fair and reasonable. Before the collaborative innovation of university interdisciplinary research organizations, collaborative body should have an analysis and estimate of their tasks and risks, predict the possible profit in the future.

The validity of performance evaluation not only affects the distribution of benefits of the university 
cross-disciplinary research organizations collaborative innovation, but also has an impact on the next round operation of collaborative innovation. Therefore, the real reasonable evaluation focuses on both results and procedure. So performance evaluation not only includes mechanism for collaborative innovation performance of the final evaluation, also includes the mechanism super visioning the operation of the collaborative innovation process. "Performance regulation mainly inspects whether the collaborative innovation goals are achieved, or the spiraling rise of collaborative innovation, focusing on academic value, service value, evaluation of users' experience(Shan Ming Feng \& Ma Jun,2013)." No regulatory means of out of control. Regulatory assessment throughout the whole collaborative innovation process, focuses on the daily management and assessment, mainly checking on whether there exists irregular default behavior of each collaborative innovation subject, whether collaborative innovation subjects are managed under the rules, whether the financial accounts are clear, whether the supervision are in place, and so on. Therefore, strengthening the process management of collaborative innovation of the interdisciplinary research organizations, establishing the regulatory risk guarantee system, periodically monitoring the implementation of the project schedule, completed quality, research efficiency, investment returns, etc, are able to achieve the dynamic, diversified inspecting on the whole process of the collaborative innovation, and to achieve dynamic regulation and norms.

The performance evaluation should obey the principle that the evaluation way should be fair and diversified. Firstly, the subject of evaluation should be variety. It is necessary to change the current evaluation modular that excusive departments and higher authorities take charge of the evaluation to a multiple evaluation system involved with experts counsel and third-party rating agencies. Secondly, the content of evaluation should be diversified. Strengthen the evaluation guide; change the appraisal methods simply according to the number of projects and papers. Because the collaborative innovation concentrates on "three directions", the performance evaluation must also be guided on the following three rules: Firstly, the quality of the original innovation. Secondly, it should meet the national needs. At last, it should meet the social needs. According to different collaborative subjects, the content evaluated should be different. For basic research-oriented collaborative innovation projects, the performance evaluation index should focus on academic values.

\section{Acknowledgements}

This work is partially supported by funding from National Natural Science Foundation of China grants (Project Grant Number.: 71240010) in 2012.

\section{References}

He Yubing. (2012). theoretical model of collaborative innovation research. Science Studies, (2): 165-174.

Li Zuchao, Liang Chunxiao. (2012). Operation Mechanism of Collaborative Innovation - Based on the main innovation Universities. Chinese Higher Education Research, (7): 81-84.

Lu Ruoyu. (2002). The mechanism of U-I cooperative innovation. Tsinghua University.

Luo Yan. (2009). the dawn local colleges and research cooperation mode and operation mechanism. Sichuan Bashu Publishing Group Press, 150-153.

Shan Ming Feng \& Ma Jun. (2013). effective operational mechanism and the driving force of collaborative innovation research universities. Education Forum, (4): 64-68.

Yanxiong. (2007). Five research collaborative innovation issues must be tackled. China High-Tech Industry Review.

Ye Shi man. (2012). collaborative innovation: the strategic choice to enhance the innovation capacity of universities. Universities and Technology of China, (3): 16-19.

Zhang Yuchen. (2011). Construction of collaborative innovation management system. Science and Technology Daily, $10-17$. 